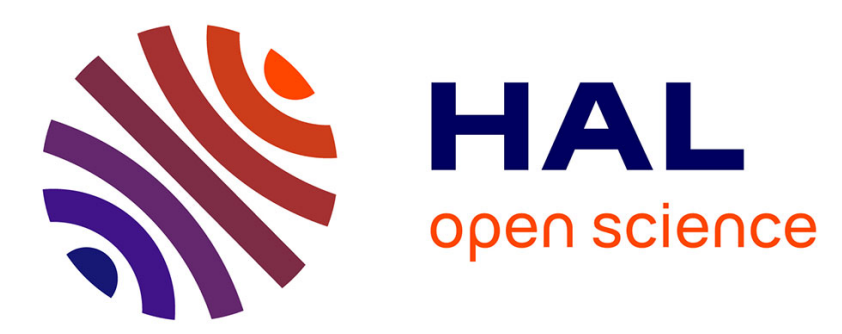

\title{
Computer-Aided Selection of Participatory Design Methods
}

\author{
Michael Bojko, Ralph Riedel, Mandy Tawalbeh
}

\section{To cite this version:}

Michael Bojko, Ralph Riedel, Mandy Tawalbeh. Computer-Aided Selection of Participatory Design Methods. IFIP International Conference on Advances in Production Management Systems (APMS), Sep 2019, Austin, TX, United States. pp.466-474, 10.1007/978-3-030-29996-5_54 . hal-02460479

\section{HAL Id: hal-02460479 \\ https://hal.inria.fr/hal-02460479}

Submitted on 30 Jan 2020

HAL is a multi-disciplinary open access archive for the deposit and dissemination of scientific research documents, whether they are published or not. The documents may come from teaching and research institutions in France or abroad, or from public or private research centers.
L'archive ouverte pluridisciplinaire HAL, est destinée au dépôt et à la diffusion de documents scientifiques de niveau recherche, publiés ou non, émanant des établissements d'enseignement et de recherche français ou étrangers, des laboratoires publics ou privés. 


\title{
Computer-aided Selection of Participatory Design Methods
}

\author{
Michael Bojko, Ralph Riedel ${ }^{(\bowtie)}$ and Mandy Tawalbeh \\ Department of Factory Planning and Factory Management, Chemnitz University of \\ Technology, Chemnitz, Germany \\ \{michael.bojko; ralph.riedel; mandy.tawalbeh\}@mb.tu-chemnitz.de
}

\begin{abstract}
The activities to introduce Industry 4.0 and Digitalization into manufacturing environments imply a multitude of new systems and technologies which change work environments and tasks that are existing there up to now. In order to cope with the increasing complexity, employees in production must be transferred into knowledge workers. This requires new approaches of work organization, training and education, and the active involvement of employees in shaping future workplaces and processes. To achieve these goals new approaches and methods for collaborative design and reorganization of workplaces and processes involving employees by means of participatory design need to be developed and implemented. Due to the large number of available methods, targeted support for the workers is required for selecting suitable methods. In this paper, the motivation and reasons to use participatory design are explained, an approach to support method selection is developed, and a computer-aided selection procedure for empowering the responsible persons on the shop floors is presented. Following, this is the basis for applications in an industrial context, where the solution can be validated and improved based on practical experiences.
\end{abstract}

Keywords: Participatory Design, Knowledge Management, Method Selection.

\section{Collaborative Workplace and Process Design Methods to empower and engage Employees}

Against the background of current activities in research and corporate landscape to establish Industry 4.0 in the manufacturing sector, new working environments emerge in the factories and workshops affecting directly the workers employed there [1-3]. These emerging changes will lead to new demands on employees in the medium to long term. In order to cope with future tasks and to master the increasing number of systems and information, the employees are further developed into so-called knowledge workers [2, 4]. Therefore, the EU-funded research project Factory2Fit focuses in particular on the design of sustainable and adaptive production environments involving employees as well as the prerequisites and methods necessary for achieving these goals. In the following, the developed concepts and tools in the project for involving and empowering workers by means of Participatory Design (PD) will be presented. PD is a systematic 
approach for designing workplaces and processes involving well-experiences employees. It has an advantageous effect on the quality and adaptability of the solutions achieved. Hence, a positive impact on the success of the company as well as on the wellbeing of workers grow up [5-7]. In addition, this approach leads to greater transparency towards those involved with regard to the solutions found and their respective suitability for fulfilling the task at hand. This transparency in turn creates acceptance for the final solution among the workers and also contributes to the understanding of future users regarding tasks and roles during the design [5].

Since the introduction of PD, a large number of methods have been established to achieve these goals in the field of workplace and process design [8], but there is a lack of support in finding and selecting the right method for a particular situation. Therefore, maintaining an overview of all available PD methods is rather difficult. In many cases people assigned with optimization or planning projects - as for instance in the piloting companies of Factory2Fit - have limited experiences with the PD approach. This results in difficulties in selecting the most suitable method for a given application and use case. The challenge for those persons is not only the size of the literature pool, but also the correct task definition and the uniqueness of the respective company. Despite all these obstacles, companies and worker representatives recognize the need to address this issue $[9,10]$. Positive effects on the success of the company result from meeting the challenges of demographic changes at the same time. The expectations of the new generation of employees in terms of adequate as well as flexible involvement and participation are considered. For this reason, a suitable procedure, preferably implemented in a manageable tool, is required for the selection of suitable PD methods, which takes the above challenges into account. With respect to the increasing digitalization and affinity of employees for digital solutions [11] and in order to limit the time required while ensuring the greatest possible user friendliness, it is advisable to implement a computerbased method selection.

\section{Classification of Participatory Design Methods}

\subsection{Elements for Structuring the Participatory Design Method Cube}

The development of a suitable procedure for the selection of PD methods is based on a model for classifying and describing the methods from the field of application. Literature shows a great variety of methodological approaches for the implementation of PD, since the established methods are suitable for a wide range of topics [8]. As the selection of the most appropriate method occurs to be a multidimensional problem, we created a model in a three-dimensional space, as this is barely visually processible by humans. Therefore, the PD method cube was derived to support the classification and selection of suitable PD methods for specific contexts with reasonable effort. The main aspects incorporated in the PD method cube are shown in Fig. 1.

A pre-selection of suitable methods can be made on the basis of the team composition and the knowledge of the individual participants. In addition, the point of application within the innovation cycle is crucial in order to identify suitable methods. [12] 


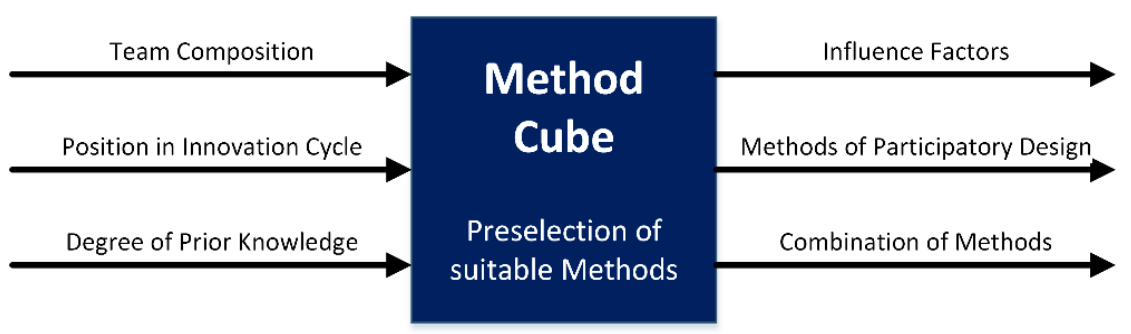

Fig. 1. Main aspects for the development of the Participatory Design Method Cube

\subsection{Attendees of Participatory Workshops in a Factory Context}

Since there are no hierarchical or educational restrictions on participation, the suitability of methods corresponds with the composition of the group of attendees. Even though Factory2Fit's primary goal is to involve factory workers with different professions, knowledge and responsibilities, they are also supported by e.g. factory planners or other experts during the workshops. Therefore, the possibly participating stakeholders have to be identified for the pre-selection of suitable methods. Three main criteria have been defined to describe the knowledge base of the group of participants:

- Company affiliation (internal vs. external):

The company affiliation describes the positions of the participants. For example, a participant originating from the same company or department where the workshop is conducted has advanced knowledge of processes, hierarchies, corporate culture and other characteristics of the organization. Participants from outside the company or department, on the other hand, usually only have general knowledge or knowledge of the organization where they work at.

- Distribution of basic knowledge within the group (homogeneous vs. heterogeneous): The general distribution of knowledge describes the subject areas and their extent of representation in the participant group. The relevant perspectives, such as methodological, hierarchical or role knowledge, must be chosen case-by-case basis according to the objectives.

- Previous knowledge of the subject matter (uninitiated vs. experts):

The previous knowledge refers to the context of the application of the method and describes the need for prior knowledge building in order to generate a common understanding on the topic.

\subsection{Structuring the Participatory Design Method Cube}

Starting from the relevant aspects for conducting a pre-selection, the method cube is divided into three dimensions: 1) Team composition, 2) Position in the innovation cycle and 3) Degree of prior knowledge [8]. They represent the main selection criteria for identifying suitable methods in the field of PD. Fig. 2 shows the model developed for shaping the PD method cube, the dimensions and characteristics represented in the PD 
method cube as well as one of the sub-cubes. As demonstrated, three main levels or perspectives are represented by the method cube:

- Target perspective:

In general, the "target perspective" results from the methodological overview and provides suitable procedures with reference to the prerequisites and intended results. The more a design task has proceeded with regards to the innovation cycle, the more details are available due to the achieved progress.

- Team perspective:

The "team perspective" covers the participants and their knowledge base. The knowledge base refers to the explicit knowledge and experience with the process or workplace to be adapted and/or optimized during the design process. Depending on the origin of the participants, different procedures need to be applied.

- Competence perspective:

The "competence perspective" combines the previous knowledge of the participants with the innovation cycle phase in its view and thus allows to match methods to achieve the defined goals with the skill of the participants.

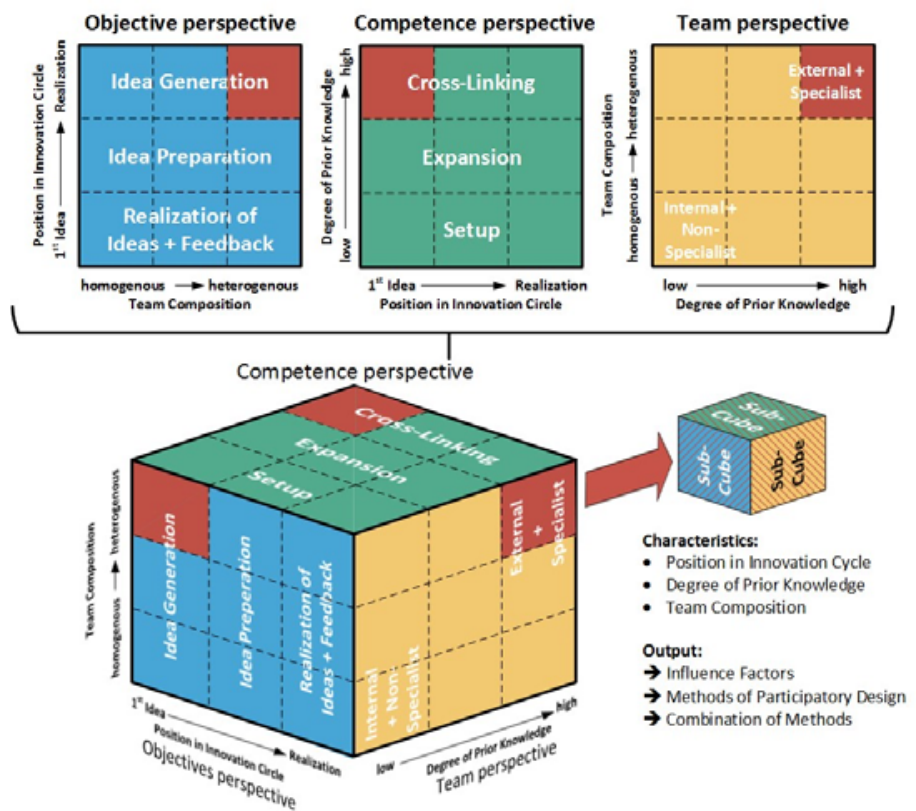

Fig. 2. Dimensions and Levels of the Participatory Design Method Cube

The three perspectives are necessary to illustrate all interdependencies between the participants' knowledge and origin as well as considering the context and objectives of the design process. The main principle of the method cube is the subdivision of the solution space into 27 sub-cubes. Each of them has a defined innovation cycle phase and is characterized by a team composition as well as the available knowledge of the participants. Suitable methods for the implementation of PD, including their sequence and combination, are determined based on the actual situation. To simplify the usage of the 
framework presented and to assist factory workers in identifying suitable PD methods, a computer-aided procedure has been developed and implemented prototypically.

\section{Designing the Computer-aided Selection Tool}

\subsection{Definition and Refinement of the Selection Criteria}

With the classification of PD methods presented in Section 2 and the derived PD method cube as the initial support, a targeted, computer-aided selection procedure requires further detailing of the dimensions incorporated in the model. For this purpose, the PD method collection planned to be utilized for the Factory2Fit project first was completed. The considered methods are examined with regard to their characteristic properties, e.g. application context, object of investigation and prerequisites. Thus a further subdivision of the dimensions was derived. In the following, the derived criteria as well as their contribution to the method selection are explained.

\section{- Object-related Method Selection}

The object of a design process is relevant for the applicability of specific methods, so that this criterion serves as an exclusion criterion. While certain methods, such as Cardboard Engineering, have been established for e.g. the investigation and optimization of assembly workstations, these methods are not or only partially suitable for the determination and revision of cycle or process times for automated systems.

\section{- Time-related Method Selection}

An approach developed earlier in our research group for selecting quality methods classifies the methods contained in the pool with regard to their phase-related use. This has proven to be a well-suited approach for the classification and selection of methods. This well-suited approach for the classification and selection of methods needs to consider the point of method application to determine the selection criterion for in-corporation. Therefore, the main demands are the time-related understanding and significance by usage across industries. For this reason, the phases of the innovation cycle also used in the PD method cube framework are the basis for classification in the selection procedure.

\section{- Participant-related Method Selection}

In addition to the criteria already set out, the target group of participants provides further important information for the precise selection of a suitable method. In particular the number of participants has a direct effect on the manner how the workshop will be designed. For example, due to the fact that the chosen method(s) must be feasible for the expected group size while delivering the desired results. In addition to considering the number of participants, it is important to consider the group composition(s) for the success of the method application. While some methods, such as Brainstorming, benefit from a heterogeneous group composition, other methods, e.g. Focus Groups, require a homogeneous composition. Depending on the context and objective of a task, the evaluation of the group composition with regard to the participants' affiliations to organisations, product lines or process chains is therefore considered as relevant. 
- Knowledge-based Method Selection

Besides the origin of the participants, the available knowledge also plays a decisive role when selecting suitable methods. Depending on the task at hand and the required group composition, the organisation, product, process or method-related knowledge of the attendees ranges from homogeneous to very heterogeneous. Particularly in the context of open innovation and the inclusion of interdisciplinary teams across organizational boundaries, heterogeneity is deliberately increasing.

- Resource-based Method Selection

Additional important aspects for those people responsible for selecting methods are the constraints set by the methods and the resources required for their implementation. Two distinct constellations during method selection can occur: 1) The application of the method is planned for the future and the resources required can be provided within time; 2) The application of the method has to take place ad hoc or the resources available are fixed and only existing means can be utilized. If there is a limited availability of resources, the user can specify the available resources for the method selection. The procedure is able to identify and exclude methods that cannot be conducted. Otherwise, the required resources do not represent a restriction; so a "no restrictions" option has been provided in the selection procedure. The evaluation of the suitability of the methods based on the constraints is omitted in this case.

The criteria derived for the PD method selection tool as well as the selectable options for the users are shown in the excerpt of the tools' user interface in Fig. 3.

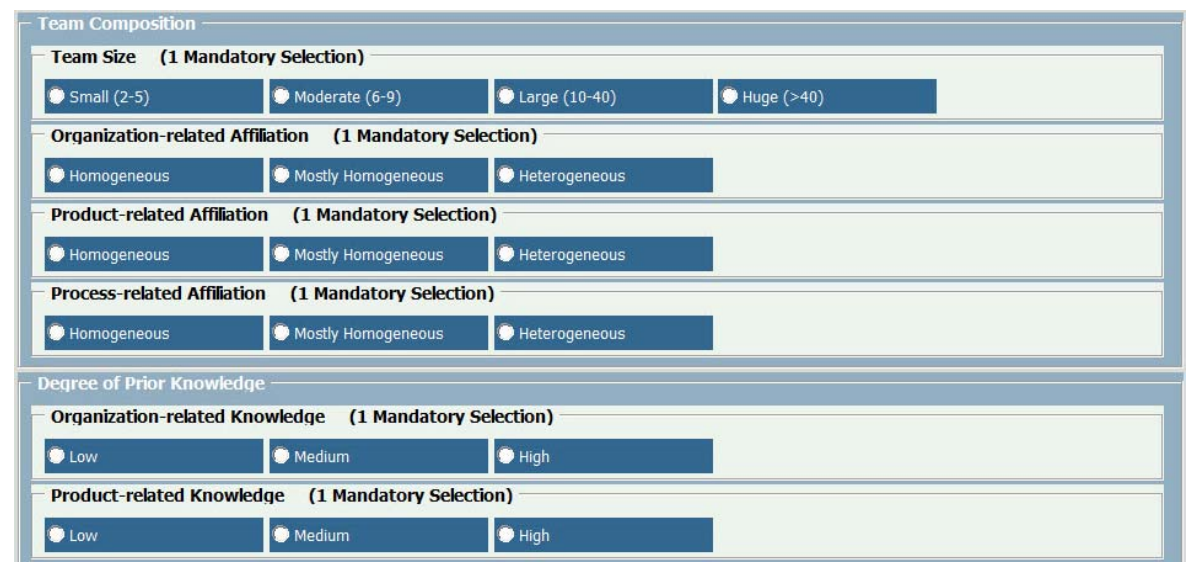

Fig. 3. Excerpt of the User Interface of the Participatory Design Method Selection Tool

\subsection{Implementation of the Procedure for Participatory Design Methods}

The demands regarding cross-industry applicability and ease of use of the procedure were also applied to the prototypical implementation by using Microsoft Excel, the spreadsheet program widely used in industry. This makes it easy to implement the logic and to validate the selection procedure in case studies without requiring the pilots to purchase e.g. additional software. In addition, all licenses of the Microsoft Office package also include the integrated development environment Visual Basic for Applications 
(VBA), which enables the implementation of extensive logics and functions [13]. This environment was utilized to create both the storage for the classification information and the user-friendly display of the criteria and their respective characteristics in a user interface. All categories and characteristics are illustrated by means of the office suite and were supplemented with short explanatory notes for better understanding. In order to be able to execute the selection procedure, the logics for the categories and/or characteristics and the considered methods need to be made available in the tool. The provision of the decision base by experienced experts and the easy-to-use input mask of the selection tool enable even non-trained employees to identify suitable PD methods. This contributes to the expansion of application and acceptance of PD in the industrial environment and thus strengthen the involvement and empowerment of workers.

\section{$4 \quad$ Summary and Future Plans}

Against the background of the goal of involving employees in the production environments in the design of workplaces and processes, PD was presented as a suitable approach for the Factory2Fit project. Due to the large number of PD methods, the lack of method selection procedures and the limited experience of responsible persons in the companies, the targeted selection of suitable methods for the various tasks is quite difficult. In order to meet this initial situation, a classification procedure for the targeted selection of PD methods was developed and mapped as PD Method Cube. In order to reduce the effort involved in the targeted selection of methods, the developed classification procedure was subsequently implemented as a computer-aided tool using Microsoft Excel and VBA. The dimensions of the method cube for this were further detailed and an user interface was designed to simplify the execution of the method selection. In this way, the gap between theory and practice is bridged and the targeted use of PD methods in the case studies is enabled. In the further course of Factory2Fit, the presented results will be piloted under real conditions; the selection procedure for PD methods will be introduced and the further development of the prototype will be promoted with the involvement of the users. The first workshops conducted with workers at the pilot sites as well as with worker representatives to introduce the concept and tools showed positive attitudes as well as anticipations of the participants towards the utilization of PD [9]. The insights gained from the feedback form the basis for a future implementation of the approach as a web-based decision support system. The webbased design of the final system also provides the framework for the integration of further functionalities, such as the direct exchange between PD experts and method users or algorithms for improving the task-related evaluation of method suitability.

\section{Acknowledgement}

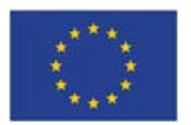

The Factory2Fit project has received funding from Horizon 2020 (H2020/2014-2020), the European Union's Programme for Research and Innovation under grant agreement $n^{\circ} 723277$. 


\section{References}

1. Bundesministerium für Arbeit und Soziales (BMAS): Weissbuch Arbeiten 4.0, Berlin (2017)

2. Bundesministerium für Wirtschaft und Energie (BMWi): Zukunft der Arbeit in Industrie 4.0, Berlin (2014)

3. Kagermann, H., Wahlster, W., Helbig, J., Deutsche Akademie der Technikwissenschaften e.V. (acatech): Deutschlands Zukunft als Produktionsstandort sichern. Umsetzungsempfehlungen für das Zukunftsprojekt Industrie 4.0. Abschlussbericht des Arbeitskreises Industrie 4.0 (2013).

4. Factory2Fit Consortium: Factory2Fit - Empowering and participatory adaptation of factory automation to fit for workers. Description of the Action (2016).

5. Riedel, R., Schmalfuß, F., Bojko, M., Mach, S.: Flexible Automatisierung in Abhängigkeit von Mitarbeiterkompetenzen und -beanspruchung. In: Gesellschaft für Arbeitswissenschaft e.V. (GfA) (ed.) Dokumentation der Herbstkonferenz der Gesellschaft für Arbeitswissenschaft e.V.; 28. und 29. September 2017 in Chemnitz. GfA-Press, Dortmund (2017).

6. Vink, P., Koningsveld, E. A. P., Molenbroek, J. F.: Positive outcomes of participatory ergonomics in terms of greater comfort and higher productivity. Applied ergonomics (2006).

7. Abildgaard, J. S., Hasson, H., Thiele Schwarz, U. von, Løvseth, L. T., Ala-Laurinaho, A., Nielsen, K.: Forms of participation: The development and application of a conceptual model of participation in work environment interventions. Economic and Industrial Democracy (2018).

8. Tawalbeh, M., Riedel, R., Horler, S., Müller, E.: Case Studies of Participatory Design. In: Lödding, H., Riedel, R., Thoben, K.-D., Cieminski, G. von, Kiritsis, D. (eds.) Advances in Production Management Systems. The Path to Intelligent, Collaborative and Sustainable Manufacturing, vol. 514. IFIP Advances in Information and Communication Technology, pp. 159-167. Springer International Publishing, Cham (2017).

9. Kaasinen, E., Schmalfuß, F., Özturk, C., Aromaa, S., Boubekeur, M., Heilala, J., Heikkilä, P., Kuula, T., Liinasuo, M., Mach, S., Mehta, R., Petäjä, E., Walter, T.: Empowering and engaging industrial workers with Operator 4.0 solutions. Computers \& Industrial Engineering (2019).

10. Aromaa, S., Liinasuo, M., Kaasinen, E., Bojko, M., Schmalfuß, F., Apostolakis, K.C., Zarpalas, D., Daras, P., Özturk, C., Boubekeuer, M.: User Evaluation of Industry 4.0 Concepts for Worker Engagement. In: Ahram, T., Karwowski, W., Taiar, R. (eds.) Human Systems Engineering and Design, vol. 876. Advances in Intelligent Systems and Computing, pp. 34-40. Springer International Publishing, Cham (2019).

11. Boes, A., Bultemeier, A., Gül, K., Kämpf, T., Langes, B., Marrs, K., Ziegler, A.: Zwischen Empowerment und digitalem Fließband: Das Unternehmen der Zukunft in der digitalen Gesellschaft. In: Sattelberger, T., Welpe, I., Boes, A. (eds.) Das demokratische Unternehmen. Neue Arbeits- und Führungskulturen im Zeitalter digitaler Wirtschaft, pp. 57-76. HaufeLexware, Freiburg (2015).

12. Chen, X., Riedel, R., Bojko, M., Tawalbeh, M., Müller, E.: Knowledge Management as an Important Tool in Participatory Design. In: Moon, I., Lee, G.M., Park, J., Kiritsis, D., Cieminski, G. von (eds.) Advances in Production Management Systems. Production Management for Data-Driven, Intelligent, Collaborative, and Sustainable Manufacturing, vol. 535. IFIP Advances in Information and Communication Technology, pp. 541-548. Springer International Publishing, Cham (2018).

13. Morgado, F.: Programming Excel with VBA. A practical real-world guide. Apress; Distributed by Springer Science+Business Media New York, New York (2016). 